\title{
AUTOMATION IN AGRICULTURE FIELD USING ARM 7 BASED ROBOT
}

\author{
Praveen Kumar Singh ${ }^{1}$, Gaurav S Nikam², Rupali S Kad ${ }^{3}$ \\ ${ }^{I}$ Dept. of E\&TC, Pimpri Chinchwad College of Engineering, Pune, Maharashtra, India \\ ${ }^{2}$ Dept. of E\&TC, Pimpri Chinchwad College of Engineering, Pune, Maharashtra, India \\ ${ }^{3}$ Dept. of E\&TC, Pimpri Chinchwad College of Engineering, Pune, Maharashtra, India
}

\begin{abstract}
This paper is about the smart agriculture robot which superimposed the all types of huddles in farming issues, for which the web of several adverse system are interfaced, the most important issue of the farming are water resource management, conservation and watering on the plant in the appropriate manner with exact quantity. In which the second obstacle strikes is the exact quantity and proportion. which is going to be detected by the soil moisture sensor. The water sprinkling is done by the robot on the response of moisture reading, using water sprinkler. The sensitivity curve of moisture sensor is drafted by analysis of the soil moisture sensor is shown, simulation result of system along with the circuit diagram are presented, working algorithm is also explained which is designed such as to work simultaneously in association with the system.
\end{abstract}

Keywords- farming water resourcemen; soil moisture sensor; water sprinkler; AVR ATMEGA 8; ARM LPC2138. ****

\section{INTRODUCTION}

Smart farming robot is the integrated system which execute several operation simultaneously to resolve the issues of farming, which are causing the. Huge trouble now a days in the society of farmers, the farming robot is the concept of movable individual body linked with the sensing on field mechanism using RF technology. The sensor used in the on field system is soil moisture sensor. Which detects the exact soil moisture value from the soil, and gives the reading in terms of voltages both analog and digital, the AVR controller interfaced RF technology the transmit the signal to the movable robot which is sprinkles water on soil. Planted with plants by the algorithm which calculate water amount required per meter area for the field, this movable system which receive the value of soil, calculate the amount of water required to sprinkle and sprinkles the water using water pump system is all interfaced on the ARM-7 LPC 2148 processor.

As mentioned above, AUTO FARMER is one of the mean machine project improving irrigation efficiency. The automated irrigation system hereby reported, consists of soil moisture sensor, linked via RF module that allowed the transfer of soil moisture data implement the robot to move to its desired position and according to the moisture value, water motors operates.

\section{ON FIELD WIRELESS SENSING}

\section{MECHANISM}

A wireless sensor unit is comprised of a RF module, soil moisture sensor a AVR controller, LCD and power supply. Several WSUs can be implemented in the field to configure presence of moisture content using this method we cover the large are of agriculture field for efficient irrigation .This unit based on the controller atmega 8 (Microchip technologies) that controls the RF module $314 \mathrm{MHz}$ These components are powered by $200 \mathrm{~mA}$ and $5 \mathrm{v}$ power supply. The controller, RF module, Power supply and electronic Component were encapsulated in a waterproof container. The schematic diagram of the sensor, RF and controller interface is depicted in Fig.1.

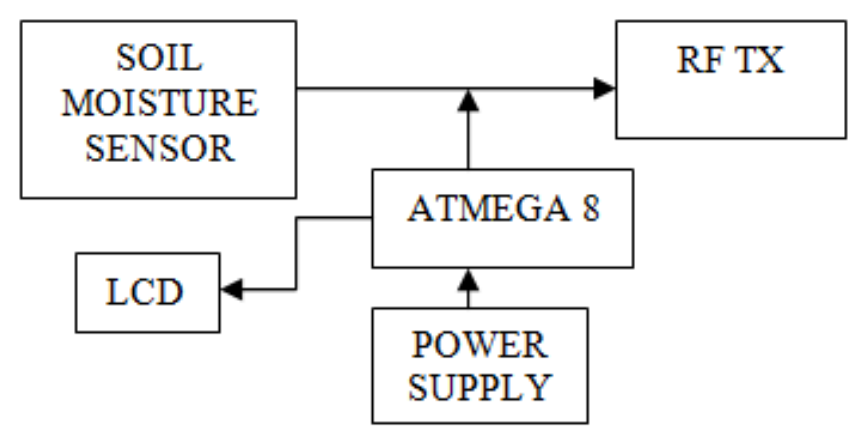

Fig.1 On Field Wireless Sensing unit Mechanism

\section{HARDWARE DESIGN}

The Robot consists of ARM-7 LPC 2148 controller. This arm based robot controls the $4 \mathrm{DC}$ motor to move, RF receiver to receive the moisture value from sensor unit and as reference value it will operate the water motor connected to sprinkler. The power supply is given to the circuit according to their requirement i.e. $12 \mathrm{v}$ for $\mathrm{dc}$ motor $5 \mathrm{v}$ for controller. LCD is interfaced with arm controller to display the moisture value received from the sensor unit. The whole circuit is again coated with waterproof container. The weight carried by robot is $3 \mathrm{~kg}$ so the, structure is made accordingly so it can carry the whole weight including robot itself. The controller 
decides when will be the pump should be turned on/off, which saves a lot of time for the farmers. This also gives much needed rest to the farmers, as they don't have to go and turn the pump on/off manually.

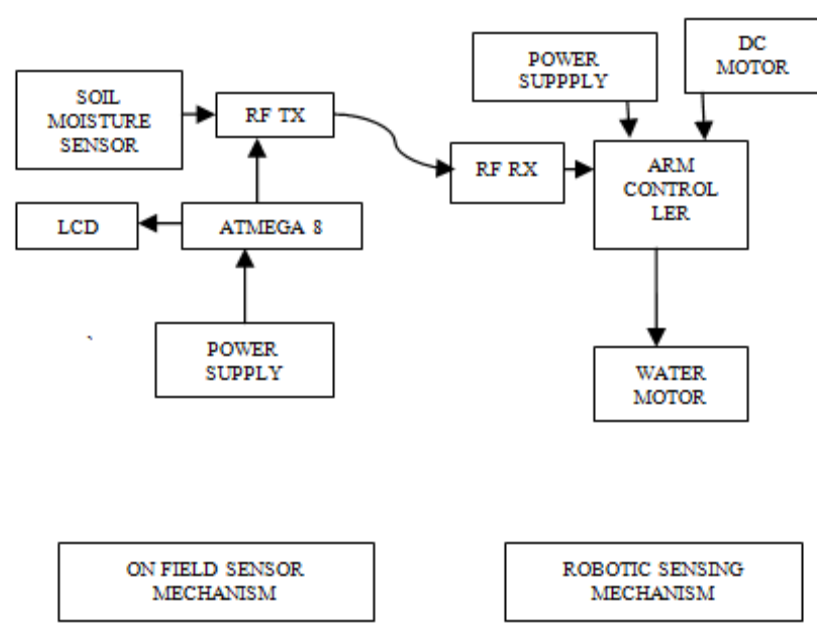

Fig .2 Block Diagram

In the given block diagram the first part is on field sensor mechanism in which the sensor record the readings in terms of voltage as the condition of field that is dry and wet condition .The sensor is inserted in the ground to the root level of plant, around $4-5 \mathrm{~cm}$, and send the reading to the RF transmitter which is interfaced with ATMEGA 8 controller, The RF transmitter is $314 \mathrm{MHz}$ use ASK modulation and transmitted at the range of $500 \mathrm{~m}$ which is suitable for small filed irrigation. LCD is interfaced to show the value of moisture level .The power supply is designed to give $5 \mathrm{v}$ power to controller, $3 \mathrm{v}$ for RF module and 3.5 volt for sensor. In our second part is robotic sensing mechanism it has $\mathrm{RF}$ receiver which accept and Decode the value from sensor mechanism. We have use arm 7 cortex LPC2138 which is fast processor to access the signal received.

The circuit shown in fig. 3 is ARM LPC2138 controller of robotic part it has 64 pin $32 \mathrm{~kb}$ of ROM, which fast and dynamic in nature other than normal controllers these controllers are also use in mobile and tablet for their dynamic features. The port 1 is interfaced $12 \mathrm{v} 200 \mathrm{~mA}$ DC motor to its motor driver L293D and RF receiver is given to pin 9. To burn the program in the controller IC it is interfaced to MAX232 IC which is serial interfaced IC to transmit and receive data from one serial port of computer to the other. We have configured to the pin 21 and 19, pin which is TX and RX property of pin. To operate the water pump it require relay, so we have use relay spdt switch, and given to pin number 52, it is a electromagnetic switch and by program feed in ARM controller. The relay turn OFF and ON the water pump according to the moisture level present in field or if the roots of the plant get enough water. This system is very much helpful in conservation of water. We have designed power supply robotic part as total power requirement is $15 \mathrm{v} 600 \mathrm{~mA}$, so we have taken $15 \mathrm{v}$ transformer, from this we have taken $12 \mathrm{v}$ for DC motor and $3 \mathrm{v}$ for $\mathrm{RF}$ receiver.

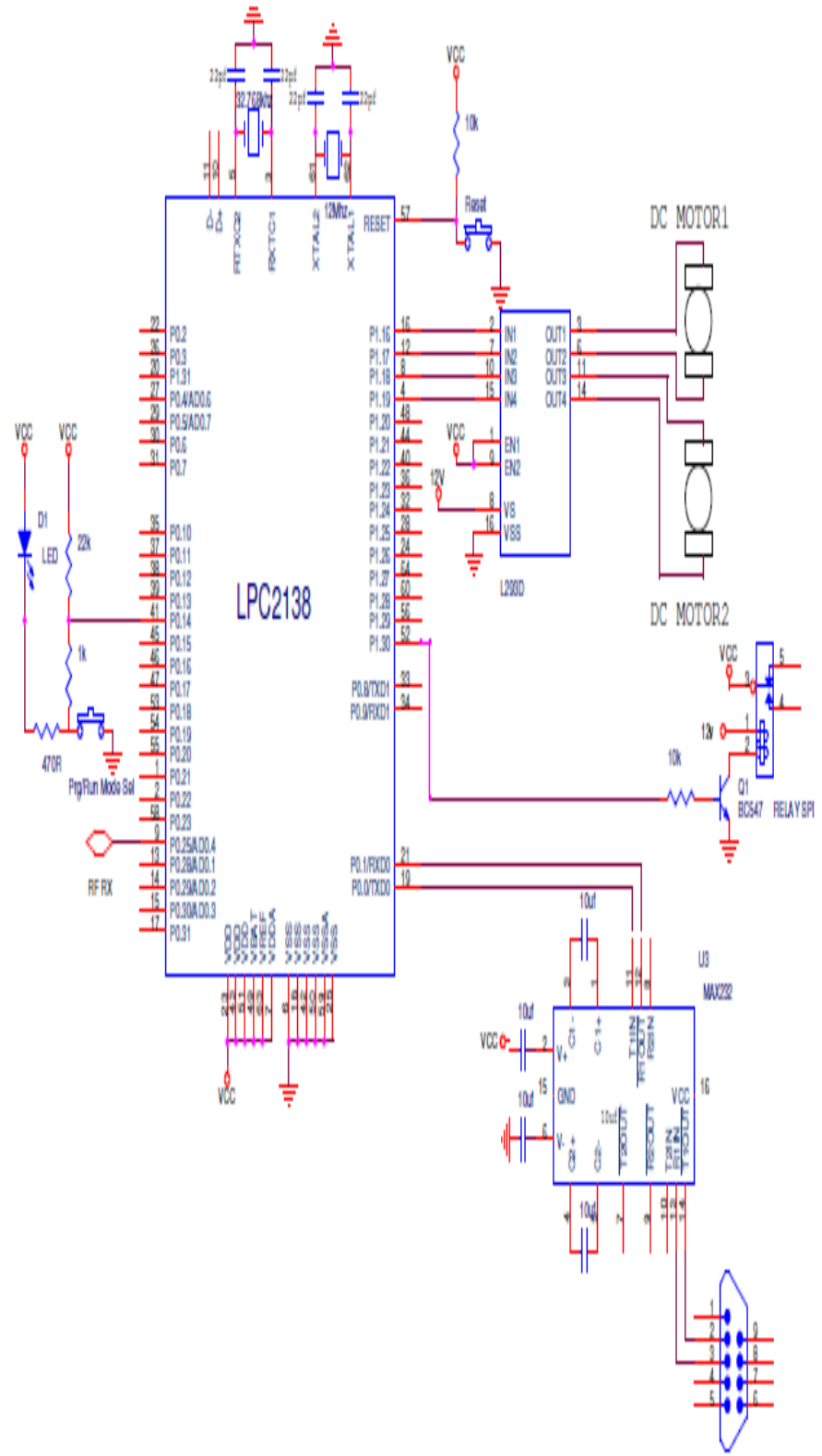

Fig .3 Circuit Diagram

\section{SOFTWARE IMPLEMENTATION}

For proper functioning and simultaneous working of both movable structure (robot) and on felid sensing mechanism . The algorithm of the system must be accurate and well hierarchy manner AVR is used to control all the peripherals. One soil moisture sensor is used to sense the moisture content of the soil. The algorithm is made according to it. The data from these sensors are fed into AVR and transmitted to the ARM LPC2138 which controls the switching of the water pump hence the flow of water to the fields.

Software use to implement this algorithms are AVR studio which simple and fast and easy to understand to design program for the available controllers that is AVR atmega 8 and ARM cortex LPC 2138. These controllers are main building blocks of whole project and the program is made in sensor value stages as described below . 


\subsection{Flowchart}

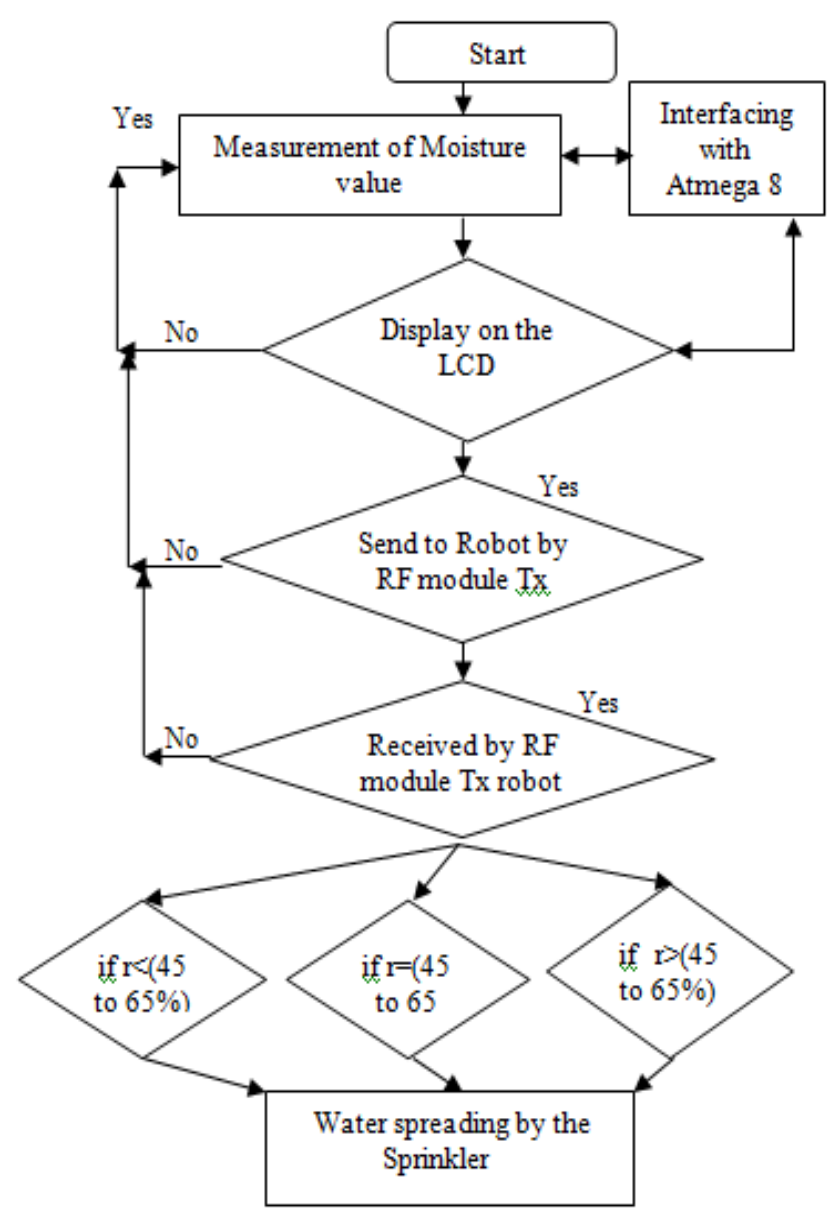

Fig 4 Flowchart

\subsection{Algorithm Stages}

Stage 1:

The Execution is as shown in the flowchart the beginning is with the on field mechanism where the on field mechanism measures the value of the moisture from the soil per unit area. The soil moisture sensor is interfaced with AVR 8 micro controller. The value of moisture is going to be processed by the Controller so it is at the same level as sensor. Value processed by AVR is then given to LCD display, to display the voltage reading taken by sensor per meter area,

\section{Stage 2:}

Then after this process the value of voltages are forward to the RF module which is also interfaced with the AVR but it is the second step of the execution of the which providing the wireless communication. Same as that RF Receiver is interfaced at the movable robot, to receive the value.

\section{Stage 3:}

After receiving the reading they are processed by the ARM 7 controller a) Processing is to divide the voltages into 3 categories

b) Output voltage range of soil moisture sensor is between 0 to 3 volt

c) So if moisture $=\mathrm{x}$

d) If $0<x<1=$ high moisture value =low output If $1<x<2=$ moderate moisture value =moderate output

If $2<x<3$ and above $=$ low moisture value $=$ high output

\section{Stage 4:}

After this processing the robot moves to the field and sprinkle the water using water sprinkler

\section{TESTING}

The testing of soil moisture sensor for different values is done and sensitivity curve is plotted according to it. Mechanical model is manufactured for robot by wooden structure

\subsection{Soil Moisture Sensor Testing:}

The soil moisture is tested under the 3 different condition in the soil of 1 meter radius area according to water level as

Table 1: Moisture Value

\begin{tabular}{|l|l|l|l|}
\hline & Low & Moderate & High \\
\hline Analog & $3 \mathrm{~V}$ & $1.4 \mathrm{~V}$ & $94.7 \mathrm{mV}$ \\
\hline Digital & 0 & 0 & $95 \mathrm{mV}$ \\
\hline
\end{tabular}

This readings are tested and observed in project lab with available equipments. We taken the soil in the jar and inserted the moisture sensor to the root level of a plant an put the water in the soil in 3 different ways that is low water, moderate and high and taken out the different reading for moisture present in soil to develop a plant. In this we have found that these values are in the range of voltage as given table.1. We have taken both reading for analog a well as digital value which is helpful to decide whether to use controller. And finally we have taken analog value given to atmega 8 which has built in ADC function.

\section{Stage 1: High Moisture Present in Soil}

In first stage we have taken a small container and with weighing $500 \mathrm{gm}$ of soil and we put $250 \mathrm{ml}$ of water. The sensor is inserted in the container and reading is taken out in DMM in this voltage is observed $95 \mathrm{mv}$ which shows the high moisture is present. 


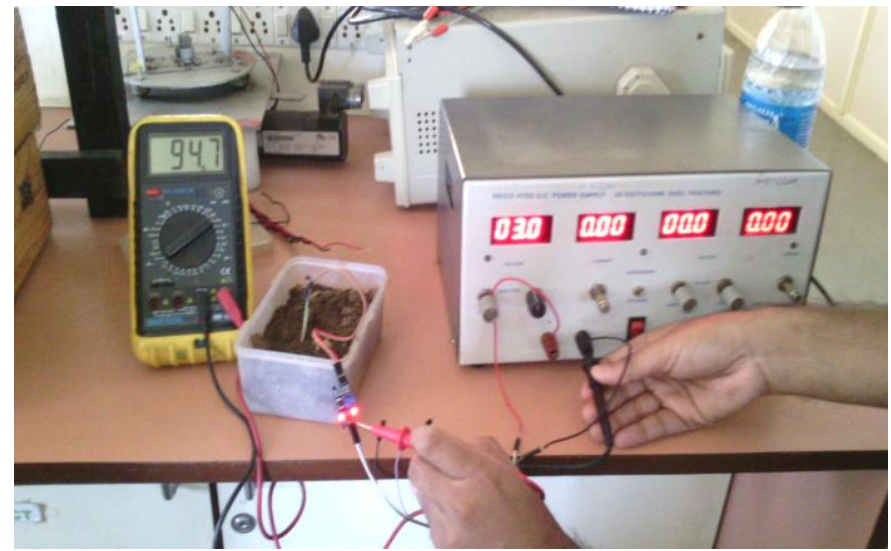

Fig 5. High Moisture

\section{Stage 2: Moderate Moisture Present in Soil}

In second stage we have taken a small container and with weighing $500 \mathrm{gm}$ of soil and we put $150 \mathrm{ml}$ of water. The sensor is inserted in the container and reading is taken out at DMM in this voltage is observed $1.4 \mathrm{v}$ which shows the moderate moisture is present.

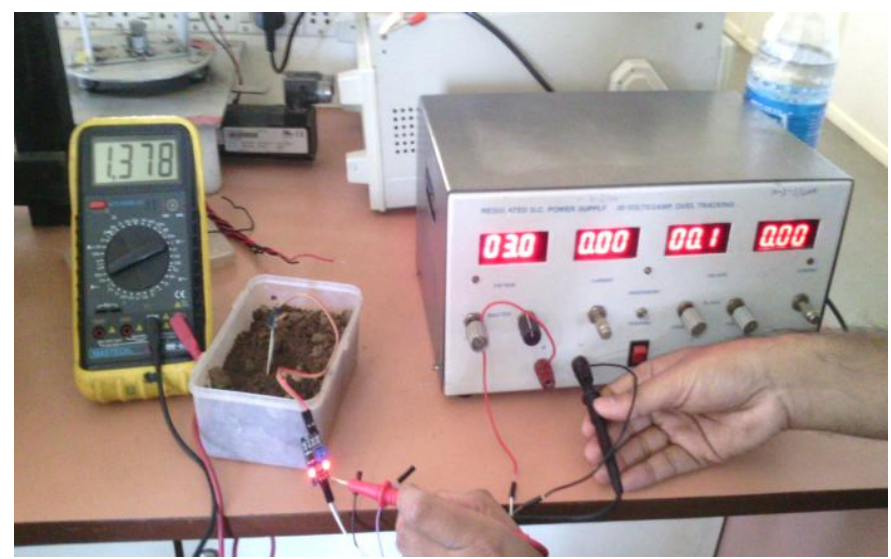

Fig 6. Moderate Moisture

\section{Stage 3: Low Moisture Present in Soil}

In second stage we have taken a small container and with weighing $500 \mathrm{gm}$ of soil and we put $70 \mathrm{ml}$ of water. The sensor is inserted in the container and reading is taken out at DMM in this voltage is observed $2.8 \mathrm{v}$ which shows the low moisture is present in the soil.

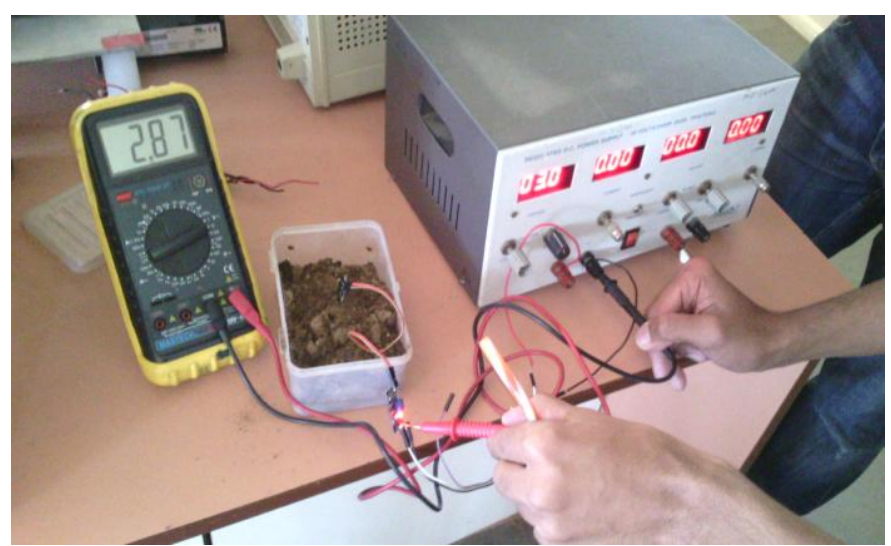

Fig 7. Low Moisture
In this way we have tested our moisture sensor at various stages of moisture present in soil and plot the characteristics graph of value found at different stages i.e, Voltage Vs moisture level shown in figure 8 .

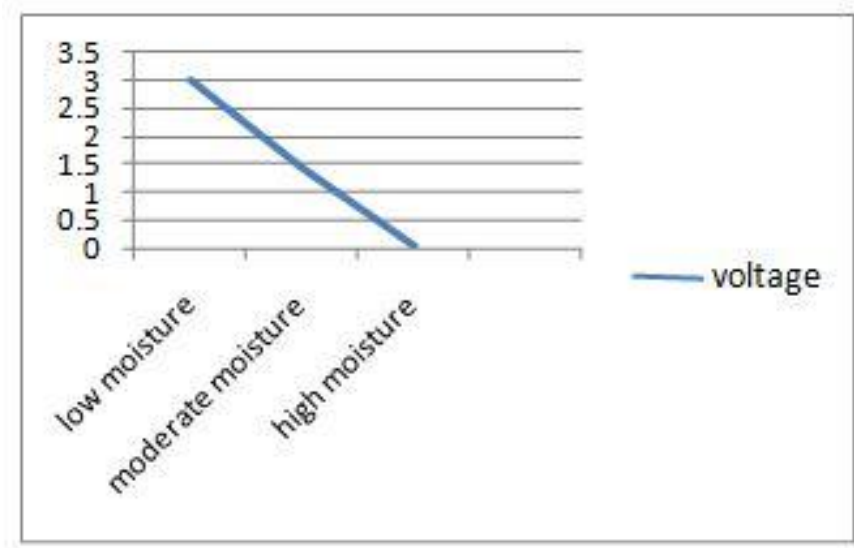

Fig 8. Characteristics Curve Of soil moisture sensor

In fig 9. We designed our final circuit for robot mechanism. The main specification of ROBOT that we have tested are:

1. Total Power Requirement 15 volt $600 \mathrm{~mA}$

2. One L293D driver for two DC motor.

3. One water pump

4. Power supply

3. Sprinkler

4. Water Pipe

5. Relay circuit

And the total weight carried by ROBOT is $3 \mathrm{~kg}$. For moving the robot two DC motor 10rpm is sufficient and wheel here use is $6 \mathrm{~cm}$ in diameter and width is taken as per to move in agriculture field. The circuit is drilled to the cardboard which is a 1 square feet in dimension an this plywood weight $500 \mathrm{gm}$ and these circuit with plywood is covered with a glass box to avoid short circuit or any damage due to water because when sprinkler start it can also destroy copper line pcb by making it short circuit.

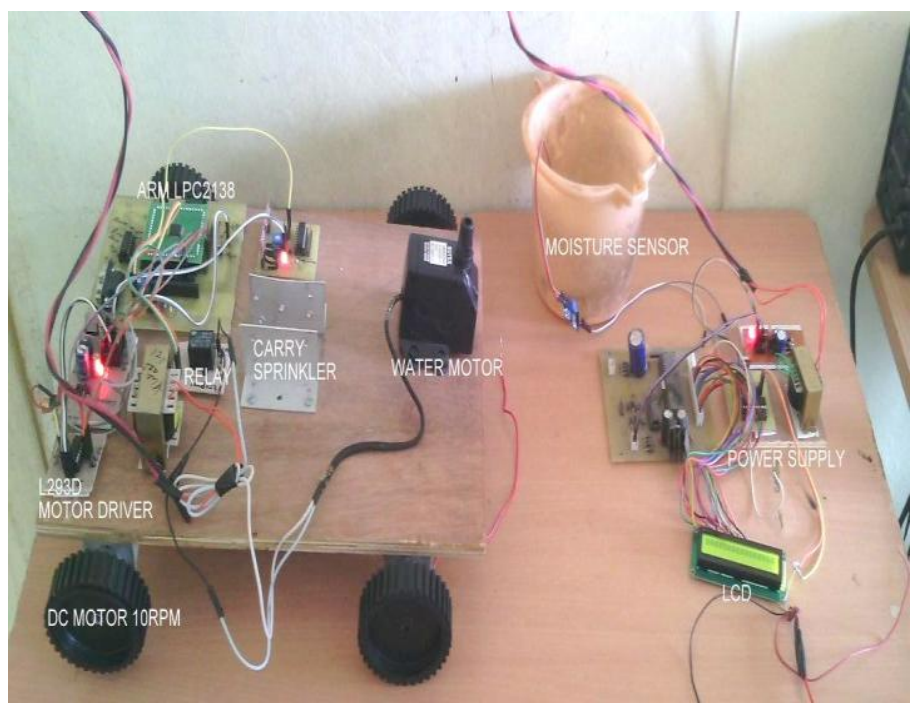

Fig 9.Final Circuit 


\section{CONCLUSION}

We established a system Automation in Agriculture Field Using ARM 7 Based Robot to overcome the problematic issues of farming. Like water resource management, accurate watering according to requirement of plant. Movable water sprinkler to reduce the cost and human efforts. By using an advance system and components developed and elite and well manner algorithm for execution. Shown all research done the, all simulation and graphs.

\section{REFERENCES}

[1] Wark.T, Corke.p,etal,"Transforming Agriculture through pervasive Wireless Sensor Networks." Pervasive computing, IEEE, 2007,6(2):pp.50-57.

[2] Stephen J. Katzberg, Omar Torres, Michael S. Grant, Dallas Masters."Utilizing calibrated GPS reflected signals to estimate soil reflectivity and dielectric constant: Results from SMEX02." Remote Sensing of Environment,2005 (100): 17-28.

[3] Caparrini,M, Egido.A; Soulat. F, Germain.O; Farres.E, Dunne.S, Ruffini. G, “Oceanpal®: Monitoring sea state with a GNSS-R coastal instrumen". Geoscience and Remote Sensing Symposium, 2007.IGARSS 2007. IEEE International, 2007 Page(s):5080 - 5083

[4] 100 Electronics projects-Bright publications.

[5] BASIC for AVR microcontrollers by -Nebojsa Matic

[6] Code Vision tutorials -Saurabh Sankule(I.I.T. Kanpur)

[7] Bull,S.R., renewable energy sources and Rural Development in Developing Countries", Proceedings of the IEEE 2001

\section{BIOGRAPHIES}

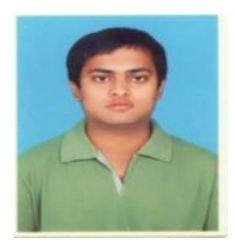

Praveen Kumar Singh, He is pursuing his degree in Pimpri Chinchwad College of Engineering, Pune

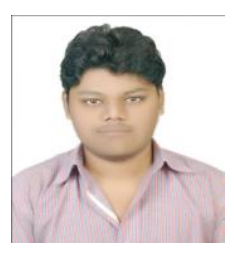

Gaurav.S. Nikam, He is pursuing his degree in Pimpri Chinchwad College of Engineering, Pune

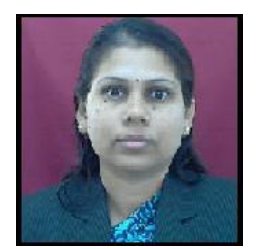

Mrs.Rupali.S.Kad, she's a Assistant Professor in Pimpri Chinchwad College Of Engineering, Pune. Her area of interest is Process Automation and Electronic instrumentation. 